\title{
Jean-Marc Larouche, La religion dans les limites de la cité. Le défi religieux des sociétés postséculières
} Montréal, Liber, 2008, 141 p.

David Koussens

\section{(Q) OpenEdition}

\section{Journals}

Édition électronique

URL : http://journals.openedition.org/assr/21156

DOI : $10.4000 /$ assr. 21156

ISSN : $1777-5825$

\section{Éditeur}

Éditions de l'EHESS

Édition imprimée

Date de publication : 31 décembre 2009

Pagination : 75-342

ISBN : 978-2-7132-2218-4

ISSN : 0335-5985

\section{Référence électronique}

David Koussens, « Jean-Marc Larouche, La religion dans les limites de la cité. Le défı religieux des sociétés postséculières ", Archives de sciences sociales des religions [En ligne], 148 | octobre-décembre 2009, document 148-79, mis en ligne le 03 juin 2009, consulté le 21 septembre 2020. URL : http:// journals.openedition.org/assr/21156 ; DOI : https://doi.org/10.4000/assr.21156

Ce document a été généré automatiquement le 21 septembre 2020

(C) Archives de sciences sociales des religions 


\title{
Jean-Marc Larouche, La religion dans les limites de la cité. Le défi religieux des sociétés postséculières
}

\author{
Montréal, Liber, 2008, 141 p.
}

\section{David Koussens}

\section{RÉFÉRENCE}

Jean-Marc Larouche, La religion dans les limites de la cité. Le défi religieux des sociétés postséculières, Montréal, Liber, 2008, $141 \mathrm{p}$.

Dans cet ouvrage, le sociologue Jean-Marc Larouche propose, à la lumière de "l'hypothèse reconstructive» (p.16) du philosophe Jean-Marc Ferry, de dépasser l'opposition moderne entre religion et raison publique pour penser la place de la religion dans l'espace public des "sociétés postséculières ", et en particulier dans la société québécoise appréhendée en tant que communauté morale et politique.

La première partie de cet ouvrage est consacrée au développement d'un cadre théorique largement inspiré de la pensée de Ferry, et dont l'objectif est d'asseoir les fondements de la thèse évoquée ci-dessus. Pour ce faire, l'auteur s'appuie sur le concept d' "identité reconstructive ", qu'il dissocie, à l'instar de Ferry, des identités narratives et interprétatives principalement fondées sur la religion, ainsi que de l'identité argumentative typique de la modernité et fondée sur la raison critique. Jean-Marc Larouche estime alors que cette identité reconstructive est caractéristique de la situation contemporaine. Elle «s'oppose [néanmoins] à l'exclusion réciproque [des deux autres formes d'identités et] permet, par son geste reconstructif, de penser leur articulation au sein d'un espace public de reconnaissance » (p. 18).

Dans une deuxième partie, l'auteur entre dans le cœur de son sujet et aborde le processus de sortie de la religion qui a affecté la société québécoise. Revenant sur certaines représentations selon lesquelles « tout se résume à associer le catholicisme à 
la période dite de la " grande noirceur » et la Révolution tranquille à l'émancipation de cet obscurantisme» (p.53), J.-M. Larouche rappelle bien que l'Église catholique québécoise est elle-même entrée dans un processus de sécularisation et de modernisation (p.54). Pour l'auteur, la religion ne s'est donc pas éclipsée mais c'est le religieux qui s'est transformé. Abordant rapidement les recompositions du catholicisme québécois au cours des dernières décennies, il se réfère aux travaux des sociologues Raymond Lemieux et Jean-Paul Montminy qui « proposent un discours sur le catholicisme qui (...) relève (...) d'une démarche d'avantage inspirée d'une philosophie sociale voire d'une éthique publique» (p. 61). Ainsi, pour l'auteur, avec cette forme nouvelle de "christianisme citoyen, se profile une conception qui déprivatise le religieux et le re-publicise au titre d'une participation à la société civile. [Il ne s'agit plus d'] une religion qui cherche à encadrer le lien social mais qui, au contraire, doit plutôt contribuer à une recomposition reconstructive du lien social » (p. 61).

J.-M. Larouche indique rejoindre «les sociologues spécialisés du christianisme contemporain (...) [qui] plaident ainsi en faveur d'une présence du religieux au sein de l'espace public tout en souscrivant au principe de laïcité » (p. 62). Il précise qu'il fait sienne la conception de Jean-Paul Willaime d'une "laïcité culturelle et citoyenne " (p. 64). Par «culturelle», Jean-Marc Larouche entend une laïcité marquée par « une culture publique partagée qui n'est rien de moins qu'une culture politique [et qui] reconnaît que nous vivons dans une société sortie de la religion» (p. 64). Cette culture politique commune se caractérise donc par «l'affirmation de l'État de droit démocratique » et la « reconnaissance des droits fondamentaux, dont celui de la liberté de religion» (p. 65). Elle est clairement dissociée de la culture morale qui, bien que porteuse de valeurs, ne correspond pas aux «raisons communes» structurant la « raison publique » (p. 65) et ne peut donc être élevée au rang de norme ou de principe régulateur. Par "citoyenne", l'auteur envisage une laïcité qui "peut miser sur la reconnaissance du fait religieux dans l'espace public [et qui] contribue à revitaliser la démocratie en faisant en sorte que les raisons de la religion puissent aussi participer à la formation d'une raison publique » (p. 64).

Lक troisième partie de cet ouvrage, dont l'objet est d'interroger les rapports entre tolérance, démocratie et liberté religieuse, est consacrée à la polémique relative à la pratique des accommodements raisonnables au Québec. Après avoir retracé certains des débats qui ont entouré cette polémique, J.-M. Larouche dégage deux figures idéaltypiques de façon de concevoir la nation et l'identité politique : d'une part, « une vision ethnoculturelle» qui correspondrait à «une vision communautarienne de la communauté politique, où les normes de la vie sociale doivent se rattacher aux valeurs essentiellement définies par la majorité historique (communauté morale)» (p. 88) et ne devraient plus être assujetties aux chartes des droits du Québec et du Canada; d'autre part, une "conception civique» qui se rapproche d'une "vision libérale de la communauté politique, où les normes politiques sont déconnectées des valeurs, exceptions faites de celles qui prennent le statut de principes régulateurs » (id.) à l'instar des chartes précitées. L'auteur retrace alors certaines des incohérences que la " conception ethnoculturelle» de la nation porte en son sein. Admettant que la charte canadienne des droits et libertés peut susciter, au Québec en particulier, de vives critiques en ce qu'elle légitime le multiculturalisme canadien, il rappelle néanmoins que la Charte des droits du Québec "n'est pas celle d'un pays étranger ", qu'elle est l' « une des balises incontournables pour juger de l'extension et des limites des droits » 
et qu'elle participe indéniablement «des raisons communes» que le Québec s'est données (p. 92).

Pøur l'auteur, c'est donc le principe de liberté de religion, garanti par les chartes, qui fonde l'obligation de neutralité de l'État et lui impose ainsi, une obligation de laïcité alors que le principe lui-même n'est affirmé dans aucune norme juridique : « sans que la laïcité soit reconnue en tant que telle dans la constitution, la neutralité en matière religieuse s'impose donc au nom des chartes canadienne et québécoise " (p. 101). Il rejette la conception d'une laïcité qui « confine[rait] la religion au privé ou lui confére[rait] un statut d'irrationalité épistémique" parce qu'ainsi, on lui «ferme[rait] l'espace public » et on " contribue[rait] à sa communautarisation voire à sa ghettoïsation" (p. 104). Il estime au contraire que la laïcité doit rencontrer les exigences du débat démocratique en accueillant, sans pour autant se renier, des registres d'expressions propres au religieux (p. 104).

J.-M. Larouche propose enfin de jeter les balises d'une " société postséculière », c'est-à-dire d'une société qui précisément dépasse l'opposition entre religion et raison publique. Pour l'auteur, « les sociétés modernes exigent (...) des traditions religieuses qu'elles puissent s'engager dans la modernisation de leur foi (...) Cette modernisation de la foi religieuse est une condition de l'insertion de celle-ci dans l'espace public » (p. 107). Il ajoute que «cette modernisation de la foi religieuse exige en retour l'ouverture de la raison séculière à la raison même de la religion ». C'est ce double mouvement qui profile l'horizon d'une "société postséculière ", c'est-à-dire celle " qui ose le passage de l'exclusion à la reconnaissance réciproque entre religion et raison publique » (p. 107). Il affirme rejoindre alors la position défendue par le républicanisme kantien, une troisième voie qui permettrait d'éviter certains des écueils du communautarisme ou du libéralisme, en faisant « de la raison publique, sous forme de discussion-délibération pratique, un " processus qui intègre les convictions de chacun dans un milieu de confrontation civilisée, ouverte et publique » » (pp. 111-112).

Pour J.-M. Larouche, la « conscience postséculière permet ainsi d'entrevoir la sortie d'une forme de laïcité, celle qui consacre l'opposition typiquement libérale entre religion et raison publique, au profit d'une autre forme qui, tout en consacrant les principes de séparation de la religion et du politique, accorde à la religion un statut épistémique et un rôle éthique irréductibles à l'irrationnel»(p.137). La laïcité citoyenne dont il se veut le promoteur se caractérise alors par la mise en avant d'une "culture publique sortie de la religion » ainsi que par la reconnaissance à la religion « de son droit de cité » (p. 137).

Le type de reconnaissance qui est ici défendu n'est pas sans rappeler une certaine pratique gallicane de cultes reconnus, et cela même si J.-M. Larouche ne propose pas d'assoir une telle reconnaissance juridiquement. Le raisonnement de l'auteur repose d'ailleurs principalement sur la façon dont le processus de sécularisation a touché la religion catholique au Québec et c'est donc bien à partir des transformations de la religion majoritaire, de la perte de la pertinence sociale et culturelle du catholicisme en tant que cadre régissant la vie morale des québécois, qu'est ici appréhendée la laïcité en tant que " laïcité citoyenne ». Dans un tel cadre, la question de la reconnaissance de religions aux pratiques plus orthodoxes reste posée.

Auofinal, l'ouvrage de J.-M. Larouche s'inscrit dans le champ de nombreuses études où l'enjeu de la régulation de la diversité religieuse n'est plus résumé à une opposition drastique entre magistères religieux et pouvoirs politiques, mais vise plutôt 
à intégrer certains des groupes religieux à la gouvernance politique. Par le cadre théorique dans lequel il s'inscrit ainsi, cet ouvrage apporte ainsi une contribution nouvelle à l'étude de la laïcité au Québec. 